\title{
The effect of childbirth preparation courses on anxiety and self-efficacy in coping with childbirth
}

\author{
Rut Khaikin, Yehudit Marcus, Shoshana Kelishek, Chaya Balik \\ Shoenbrun Academic School of Nursing, Tel-Aviv Sourasky Medical Center, Tel-Aviv, Israel
}

Received: April 13, 2016

Accepted: June 1, 2016

Online Published: June 12, 2016

DOI: $10.5430 /$ cns.v4n3p39

URL: http://dx.doi.org/10.5430/cns.v4n3p39

\begin{abstract}
Objective: To evaluate the effect of childbirth preparation courses on anxiety and self-efficacy levels in coping with childbirth. Methods: A study was conducted on a convenience sample of nulliparous women. The intervention groups consisted of 31 women who attended a 5-week childbirth preparation course and 39 women who attended a 2-week course. A control group included 32 women who did not attend any of the childbirth preparation courses. Levels of anxiety and self-efficacy were measured before and after childbirth preparation courses. The setting was a large teaching hospital in central Israel.

Results: After completing the preparation courses the anxiety level dropped significantly in the long and short course groups ( $p=.04$ and $p=.01$, respectively). The anxiety in both groups was significantly related to the self-efficacy for coping with childbirth $(r=-0.26, p=.03$ and $r=-0.48, p=.001$, respectively). Nonetheless, attending the preparation courses did not raise the level of self-efficacy in coping with childbirth. Anxiety and self-efficacy levels in the control group were not significantly different from those of the other groups.

Conclusions: Preparation courses are expected to reinforce the self-efficacy of the parturient. The overall impact of the findings indicated that while they had no effect on self-efficacy, they did constitute an anxiety-reducing factor. Midwife postgraduate programs should include training in preparing women for coping with childbirth. These findings are an important contribution to the examination of current strategies of teaching and training of midwives in conducting childbirth preparation courses.
\end{abstract}

Key Words: Childbirth preparation courses, Anxiety, Self-efficacy, Coping with childbirth

\section{INTRODUCTION}

Self-efficacy is viewed a core concept in nursing care, since it stresses the importance of empowering the patient, as well as self-management. ${ }^{[1]}$ Many researchers claim that selfefficacy of pregnant women in coping with the process of childbirth can predict their perception of pain in childbirth, level of apprehension and anxiety, and the likelihood of developing post-traumatic stress disorder following birth. ${ }^{[2-4]}$ Lowe ${ }^{[5]}$ examined the correlation between the perception of self-efficacy in coping with childbirth and the fears related to childbirth among nulliparous women. She found an inverse relationship between the levels of self-efficacy and the levels of fear related to childbirth. She also observed that women with high levels of fear opted for childbirth with epidural anesthesia, while women with low levels of fear preferred natural childbirth. Similar results were also observed in the studies conducted by Reck et al. ${ }^{[6]}$ and Beebe et al., ${ }^{[7]}$ who found a significant positive correlation between the overall anxiety level and birth- related anxiety, a significant negative correlation between the anxiety level and self-efficacy level in coping with childbirth, and a significant negative correlation between ways of coping with the childbirth process

\footnotetext{
*Correspondence: Rut Khaikin; Email: rutk@tasmc.health.gov.il; Address: Shoenbrun Academic School of Nursing, Henrietta Zold 17, Tel-Aviv, 64924, Israel.
} 
and the level of pain during childbirth. There was also a correlation between fear of childbirth, self-efficacy and the type of childbirth. Women with severe fear of childbirth were more likely to have a low score of self-efficacy expectations and to prefer a cesarean section instead of a vaginal birth. ${ }^{[3,8]}$ The level of self-efficacy also influences the type of childbirth after a previous Cesarean section. Women with low self-efficacy preferred a cesarean section in subsequent births. ${ }^{[9]}$

According to Heinze and Sleight, ${ }^{[10]}$ women who were administered epidural anesthesia in childbirth reported high levels of fear of childbirth, and their expectations were of external control and passive participation in childbirth. The degree of realization of expectations from the birth and selfefficacy was directly related to satisfaction with the childbirth in one study. ${ }^{[11]}$ Others reported that stronger feelings of selfefficacy during childbirth were predictive of decreased pain in labor and increased birth satisfaction. ${ }^{[12]}$

Based on the above, it follows that it is to essential to invest resources to reinforce self-efficacy of pregnant women in coping with childbirth and to reduce fear and anxiety levels. Childbirth preparation courses are intended to impart knowledge, empower women, advance their ability to cope with the childbirth process and positively affect the birth experience. Thus, for example, Spinelli et al. ${ }^{[13]}$ found that women who attended childbirth preparation courses reported using the tools they acquired for coping with the childbirth process, and had greater satisfaction from the childbirth process. Byrne et al. ${ }^{[14]}$ reported that participants in childbirth education programs had significantly more self-efficacy, had more positive expectations of their birth, and were less fearful of giving birth.

In contrast, several other researchers reported no connection between participation in preparation courses and perception of self-efficacy in childbirth, the use of painkillers in childbirth and satisfaction with the childbirth. ${ }^{[15-18]}$ Gagnon and Sandall ${ }^{[19]}$ conducted a methodical survey and meta-analysis on the subject of childbirth preparation courses and found nine extensive studies comprising 2,284 women. Based on their findings, the researchers concluded that the effect of the childbirth preparation courses on acquiring knowledge and affecting anxiety level, sense of self-control, perception of pain in childbirth and social and emotional adjustment seemed to be doubtful. Given the continuing controversy over this subject, the objective of the current study was to evaluate the effect of participating in childbirth preparation courses on self-efficacy and anxiety levels in coping with the childbirth process in nulliparous Israeli women.

The theoretical framework chosen for this study was Ban- dura's ${ }^{[20]}$ Social Cognitive Theory, in which he defined selfefficacy as belief in one's ability to cope with a specific task and to succeed in it. According to Bandura, the belief in one's ability to cope with a specific task affects the efforts invested in performing the task. High self-efficacy levels encourage the investment of substantial efforts toward attaining goals and determine the degree of effort and amount of time to be invested in performing the task in order to overcome the difficulties. Low self-efficacy, on the other hand, reduces motivation and leads to decreased investment of effort, giving in to difficulties and thoughts of failure. Bandura ${ }^{[20]}$ noted that self-efficacy is unrelated to one's objective abilities, but rather to one's belief in one's abilities. Moreover, Bandura $^{[21]}$ differentiated between self-efficacy and outcome expectations. A person may believe that a particular behavior may lead to expected results, but, at the same time, may feel insecure regarding his or her ability to behave in a manner that leads to the expected results.

Self-efficacy is affected by past personal experience in performing similar tasks, observing the performance of others, verbal persuasion and sensitive physical condition. Past personal experience also greatly influences the perception of self-efficacy. ${ }^{[20]}$ In the absence of a personal experience, the observation of another person undergoing that experience becomes even more significant. The perception of self-efficacy affects and plays an important role in setting objectives and goals at work and in everyday life, as well as affecting it affects desire and motivation to cope with new challenges, and facilitating effective responses to pressures and difficulties. One of Bandura's fundamental assumptions is that self-efficacy can be developed and bring about a behavioral change, the desired results, and better achievements. Based on a literature survey and on the Social Cognitive Theory, the following research assumptions were made:

(1) A difference exists between the level of self-efficacy in coping with the childbirth process before the childbirth preparation course, and the level of self-efficacy after the childbirth preparation course.

(2) A difference exists between the level of anxiety before the childbirth preparation course, and the level of anxiety after the childbirth preparation course.

(3) A correlation exists between the level of self-efficacy in coping with the childbirth process, and the level of anxiety before and after the childbirth preparation course.

\section{Methods}

\subsection{Research design and setting}

A quasi-experimental design was used to investigate the effect of childbirth preparation courses on anxiety and self- 
efficacy levels in coping with the childbirth. The setting for this study was a large public medical center in an urban area in central Israel. The medical center provides highquality maternity care during childbirth at no cost to Israeli women regardless of their race/ethnicity, religious affiliation, or socio-economic status.

\subsection{Participants}

A convenience sample was comprised of 70 pregnant women in their $33^{r d}$ to $37^{t h}$ week of pregnancy, who were participating in childbirth preparation courses before their first childbirth. The first group (long course) consisted of 31 women who attended a 5-week childbirth preparation course including a tour of the delivery room. The second group (short course) consisted of 39 women who attended a 2-week childbirth preparation course, that did not include a tour of the delivery room. The content of both types of courses was identical, but the framework of the longer course afforded greater opportunity for better interaction between the midwife and the participants, as well as more time to practice breathing and relaxation for coping with the childbirth process. The third study group (control group) consisted of 32 women who did not participate in any childbirth preparation courses whatsoever.

\subsection{Procedure}

After obtaining approval of the local Helsinki Committee, a two-stage study was conducted. In the first stage, at the start of the childbirth preparation course, the researchers met with the potential course participants, presented the study content and design and invited them to participate. The women who agreed to participate in the study signed an informed consent form and completed questionnaires related to the perception of their self-efficacy in coping with childbirth and their anxiety level. Demographic data were recorded as well. In the second stage of the study, just before the very end of the childbirth preparation course, the participants were asked to complete identical questionnaires, omitting the demographic data. The group of women who did not attend the childbirth preparation course (control group) also consisted of nulliparous women at an advanced stage of pregnancy who were admitted to the maternity hospital for follow-up and pregnancy tests, and they completed the questionnaires in the waiting room. Compliance in completing the questionnaires in all groups was high (90\%). Reasons for refusal to participate in the study were "personal".

\subsection{Research tool}

The study employed a tool consisting of the following questionnaires:

Published by Sciedu Press
(1) State-Trait Anxiety Inventory questionnaire. Developed by Spielberger, ${ }^{[22]}$ this questionnaire is composed of an Anxiety-State questionnaire and an Anxiety-Trait questionnaire. Each questionnaire may be used independently. For the purposes of the current study only the questionnaire examining the anxiety state was employed. It contains 20 items reflecting the anxiety level at a given moment. Participants were asked to grade their answers on a 4-level Likert scale, ranging from 1 - do not feel at all, to 4 - feel very strongly. Some of the items employed oppositeness and had to be inverted prior to totaling the overall score. The resultant overall score that could be obtained by a participant ranged from 20 (minimal anxiety) to 80 (maximal anxiety). The questionnaire had been translated into Hebrew, it was found to be valid and reliable, and it has been used in previous studies. ${ }^{[23]}$ In the current study, internal reliability on Cronbach's $\alpha$ index was 0.92 .

(2) Childbirth Self-Efficacy Inventory. Developed by Lowe, ${ }^{[24]}$ this questionnaire is composed of four parts. The first and second parts (31 items) relate to outcome expectations in coping with childbirth. Those parts estimate the extent to which the participant feels that the behaviors listed in the questionnaire, such as relaxation, breathing exercises, and support by companion, could assist her in coping with the first and second stages of childbirth. The third and fourth parts of the questionnaire (31 items) relate to self-efficacy expectations of coping with childbirth and estimate the extent to which the participant feels confident of her ability to employ these behaviors in coping with the first and second stages of childbirth. For each part, the participants rank their feelings about the listed behaviors on Likert 10 level scale ranging from 1 - does not help at all/uncertain, to 10 - helps a great deal /very certain. The overall range of rankings for each part (outcome expectations and self-efficacy) extends from 31 to 310. Previous studies demonstrated a significant difference between the scores of the part examining the outcome expectations and the scores of the part examining selfefficacy in favor of the outcome expectations. ${ }^{[25,26]}$ In other words, women thought that the behaviors listed in the questionnaire could assist them in coping with the childbirth process, but were not sufficiently certain of their abilities to use these behaviors during the childbirth process.

For the purpose of conducting the current study, permission was obtained from the author ${ }^{[24]}$ to use the questionnaire, 
which was professionally translated into Hebrew and back into English. The validity of the questionnaire was found to be high. The internal reliability of the questionnaire as measured by Cronbach's $\alpha$ index was 0.95 for the part examining the outcome expectations and 0.97 for the part examining self-efficacy.

\subsection{Data analysis}

The demographic characteristics of the sample were analyzed using frequencies, percentages, measures of central tendency and measures of variability based on a level of measurement. A paired $t$-test was used to compare differences in levels of anxiety and self-efficacy before and after completion of the childbirth preparation courses. Pearson's $r$ was used to study relations between anxiety and self-efficacy levels. An ANOVA method was used to compare the average anxiety and self-efficacy levels in three groups.

\section{Results}

\subsection{Demographic characteristics of the sample}

Analysis for comparing demographic variables between the three study groups examined the variable of age using the ANOVA method and other variables, such as family status, socio-economic status, degree of religiosity and the education level, using the chi-square test. The results revealed no difference between the three groups in the demographic variables, except for the educational level and the degree of religiosity. The group that attended the childbirth preparation courses in the shorter form (two weeks) consisted mostly of secular women. The two other groups were mixed and they included secular women, traditional women and religious women. The responses to the education variable of the women in the control group were considerably diverse. Only one-half had completed an academic degree, compared to the majority of the women in the study. A detailed demographic description of the three groups is presented in Table 1.

Due to differences between the groups in educational level and degree of religiosity, $t$-tests were applied to determine whether there was a difference between secular and religious women in the levels of their self-efficacy and anxiety. The same tests were used to examine whether there was a difference in the levels of self-efficacy and anxiety between women who hold academic degrees vs. women with a high school education in the levels of self-efficacy and anxiety. The findings indicate no significant difference between secular and religious women in the levels of self-efficacy and anxiety. Furthermore, there is no significant difference between the women who held an academic degree vs. the women with a high school education in the levels of self-efficacy. The only difference was in the level of anxiety between the women who held an academic degree vs. the women with a high school education $(p=.03)$.

Table 1. Demographic characteristics of the sample

\begin{tabular}{|c|c|c|c|c|}
\hline Variable & $\begin{array}{l}\text { Group } 1 \\
(\text { long course } n=31)\end{array}$ & $\begin{array}{l}\text { Group } 2 \\
\text { (short course } n=39 \text { ) }\end{array}$ & $\begin{array}{l}\text { Group } 3 \\
(\text { no course } n=32)\end{array}$ & $p$-value \\
\hline Age ( Mean $\pm S D$ ) & $29.8 \pm 3.43$ & $30 \pm 3.07$ & $30 \pm 4.46$ & .62 \\
\hline $\begin{array}{l}\text { Family Status, } n(\%) \\
\text { - Married } \\
\text { - Living with partner }\end{array}$ & $\begin{array}{l}29(94 \%) \\
2(6 \%)\end{array}$ & $\begin{array}{l}36(93 \%) \\
3(7 \%)\end{array}$ & $\begin{array}{l}29(91 \%) \\
3(9 \%)\end{array}$ & .52 \\
\hline $\begin{array}{l}\text { Socio-economic status, } \\
\text { - Low } \\
\text { - Medium } \\
\text { - High }\end{array}$ & $\begin{array}{l}- \\
26(84 \%) \\
5(16 \%)\end{array}$ & $\begin{array}{l}- \\
30(77 \%) \\
9(23 \%)\end{array}$ & $\begin{array}{l}- \\
28(88 \%) \\
4(12 \%)\end{array}$ & .61 \\
\hline $\begin{array}{l}\text { Degree of religiosity, } n \text { ( } \\
\text { - Secular } \\
\text { - Traditional/religious }\end{array}$ & $\begin{array}{l}21(68 \%) \\
10(32 \%)\end{array}$ & $\begin{array}{l}35(90 \%) \\
4(10 \%)\end{array}$ & $\begin{array}{l}22(69 \%) \\
10(31 \%)\end{array}$ & .02 \\
\hline $\begin{array}{l}\text { Education Level, } n(\%) \\
\text { - High school/+ } \\
\text { - Academic }\end{array}$ & $\begin{array}{l}5(16 \%) \\
26(84 \%)\end{array}$ & $\begin{array}{l}7(18 \%) \\
32(82 \%)\end{array}$ & $\begin{array}{l}14(41 \%) \\
18(59 \%)\end{array}$ & .03 \\
\hline
\end{tabular}

3.2 Differences between outcome and efficacy expectations

The Childbirth Self-Efficacy Inventory was examined by the $t$-test to determine its ability to distinguish between outcome expectations and self-efficacy. Similar to previous studies, ${ }^{[24]}$ the level of self-efficacy was lower than the outcome expectations in each participating group. Details of the statistical analyses of the questionnaire for purposes of estimating its ability to distinguish between the level of outcome expectations and the level of self-efficacy are presented in 
Table 2 .

\subsection{Childbirth self-efficacy before and after childbirth preparation courses}

Assumption 1 states that a difference will be found in the level of self-efficacy in coping with the childbirth process before the childbirth preparation course and the level of selfefficacy after the childbirth preparation course. Paired t tests were performed to examine that assumption, and it was refuted. The findings for Group 1 (long course) indicated an absence of a significant difference between the averages of the self-efficacy level before and after the childbirth preparation course $(t[30]=-1.15, p=.26)$. The average of self-efficacy scores after the childbirth preparation course in its long form ( $\mathrm{M}=227, S D=46.1$ ) was high, but not at a level significantly higher than the average self-efficacy score before the course $(\mathrm{M}=216, S D=49.9)$. The findings for Group 2 (short course) also indicated the absence of any significant differences between the average self-efficacy scores before and after the childbirth preparation course $(t[38]=-1.15$, $p=.20$ ). The average self-efficacy score after the childbirth preparation course in its short form $(\mathrm{M}=233, S D=44.9)$ was high, but not at a level significantly higher than the average self-efficacy score before the course $(M=221, S D=49.9)$.

A one-way ANOVA was performed in order to compare the average self-efficacy scores of women after the childbirth preparation courses both in the long and the short form with the average self-efficacy scores of women who did not participate in any childbirth preparation courses. The findings did not reveal any significant difference between the self-efficacy scores of women after the childbirth preparation courses and the self-efficacy scores of women who did not participate in any of the childbirth preparation courses $(F[2,99]=0.54$, $p=.18)$. Table 3 presents the average self-efficacy scores for each group.

Table 2. Difference between the outcome expectations and self-efficacy

\begin{tabular}{|c|c|c|c|c|}
\hline Group & Outcome Expectations & Self-Efficacy & $t$-test & $p$-value \\
\hline \multicolumn{5}{|c|}{ Before the Childbirth Preparation Course } \\
\hline - Group $1($ Mean $\pm S D)$ & $241 \pm 49.6$ & $216 \pm 49$ & $t(30)=3.53$ & .001 \\
\hline - Group $2($ Mean $\pm S D)$ & $252 \pm 35.6$ & $221 \pm 49.9$ & $t(38)=4.71$ & .000 \\
\hline \multicolumn{5}{|c|}{ After the Childbirth Preparation Course } \\
\hline - Group 1 (Mean $\pm S D)$ & $254 \pm 35.6$ & $227 \pm 46.1$ & $t(30)=4.84$ & .001 \\
\hline - Group $2($ Mean $\pm S D)$ & $256 \pm 37.8$ & $233 \pm 44.9$ & $t(38)=4.28$ & .000 \\
\hline \multicolumn{5}{|c|}{ No Childbirth Preparation Course } \\
\hline - Group $3($ Mean $\pm S D)$ & $251 \pm 35.9$ & $222 \pm 52.3$ & $t(31)=3.28$ & .003 \\
\hline
\end{tabular}

Table 3. Self-efficacy scores in each group

\begin{tabular}{llll}
\hline & Before Course & After Course & No Course \\
\hline Group 1 (Long Course) & $\mathrm{M}=216, S D=49.9$ & $\mathrm{M}=227, S D=46.1$ & ---- \\
Group 2 (Short Course) & $\mathrm{M}=221, S D=49.9$ & $\mathrm{M}=233, S D=44.9$ & $\begin{array}{l}---- \\
\text { Group 3 (No Course) }\end{array}$ \\
\hline
\end{tabular}

3.4 Anxiety level before and after the childbirth preparation course

Assumption 2 states that a difference will be found in the anxiety level before the childbirth preparation course and the anxiety level after the childbirth preparation course. Paired $t$ tests were performed to compare the findings and the results confirmed that assumption. The findings for Group 1 (long course) showed a significance difference between the average anxiety level scores before and after the childbirth preparation course $(t[30]=1.82, p=.04)$. The average anxiety level score after the childbirth preparation course in the long form $(\mathrm{M}=49.4, S D=5.2)$ was lower than the score obtained before the course $(\mathrm{M}=51.2, S D=4)$. The findings for Group 2 (short course) also indicated a significant difference between the average anxiety scores level before Published by Sciedu Press and after the childbirth preparation course $(t[38]=2.43$, $p=.01)$. The average anxiety level score after the childbirth preparation course in its short form $(\mathrm{M}=50.6, S D=5.8)$ was lower than the score before the course $(\mathrm{M}=50.6, S D=5.8)$.

A One-Way ANOVA was performed to compare the average anxiety level scores following childhood preparation courses both in the long and short form with the average anxiety level scores among women who did not participate in any childhood preparation courses. The results showed no significant difference between anxiety scores of women after the childbirth preparation courses and anxiety scores of women who did not participate in the childbirth preparation courses at all $(\mathrm{F}[2,99]=0.84, p=.55)$. Table 4 presents the average scores for each group. 
Table 4. Anxiety scores in each group

\begin{tabular}{llll}
\hline & Before Course & After Course & No Course \\
\hline Group 1 (Long Course) & $\mathrm{M}=51.2, S D=4.0$ & $\mathrm{M}=49.4, S D=5.2$ & ----- \\
Group 2 (Short Course) & $\mathrm{M}=52.2, S D=5.8$ & $\mathrm{M}=50.6, S D=5.8$ & ---- \\
Group 3 (No Course) & ---- & ---- & $\mathrm{M}=50.8, S D=4.0$ \\
\hline
\end{tabular}

\subsection{Correlation between self-efficacy and anxiety level}

Assumption 3 states that there is a link between the level of self-efficacy for coping with the childbirth process and the anxiety level before and after the childbirth preparation course. The Pearson coefficient findings partially confirmed that assumption. No significant correlation was found between the anxiety level and self-efficacy in coping with the childbirth process before the childbirth preparation course in Group 1 (long course) $(r=-0.13, p=.48)$. Following the childbirth preparation course, however, there was a significant negative correlation between the variables $(r=-0.26$, $p=.03)$. Specifically, the self-efficacy level rose as the anxiety level dropped after the childbirth preparation course in its long form, similar results were obtained in Group 2 (short course). There was no significant correlation between the anxiety level and self-efficacy in contending with the childbirth process before the course $(r=-0.25, p=.13)$, while there was a negative correlation between the variables after the childbirth preparation course $(r=-0.48, p=.001)$. Specifically, the anxiety level dropped as the self-efficacy level rose after the childbirth preparation course in the short form. There was no significant correlation between the anxiety level and self-efficacy in coping with the childbirth process in Group 3 (no childbirth preparation course) $(r=-0.26$, $p=.19)$.

\section{Discussion}

The aim of this study was to examine the effect of childbirth preparation courses on anxiety and self-efficacy in coping with the process of childbirth among nulliparous women. The study is unique in its use of a control group for the purpose of evaluating the effectiveness of childbirth preparation courses and their relevance in the era of "medicalization" and advanced medical technology. Moreover, a literature search failed to elicit any published studies carried out on these issues by means of a similar methodology.

Although the research assumptions claim that childbirth preparation courses reinforce self-efficacy in coping with the childbirth process, the study results actually indicate a rise in self-efficacy, albeit not a significant one. The lack of effect found in the study by Escott et al. ${ }^{[16]}$ as well as in the current study may be explained by the dynamics of the self-efficacy concept itself, as described by Lowe. ${ }^{[24]}$ The dynamics of the concept may stem from time gaps, as well as the timing by which the sense of self-efficacy was measured. It might be that had the measurement been carried out shortly before birth or during the birth itself, the reporting on self-efficacy would be different. It is possible that the medicalization of pregnancy and birth (i.e., conversion of the childbirth process from being natural and normative to a medical procedure managed within an acute monitored hospitalization array controlled by professionals and focused on the potential risk involved in childbirth) affects the contents and messages transmitted in the preparation courses for empowering the woman, and broadening her understanding and comprehension of the naturalness of the birth process, guided by the very medical system in which the childbirth takes place. This approach is reinforced by the findings of the current study, which indicate a significant negative correlation between anxiety and self-efficacy. Anxiety is reduced by the knowledge acquired during the course and by the knowledge gleaned by the woman from other sources. The significant drop in the anxiety level that was observed in the current study was almost certainly due to the knowledge gained, as well as to the ability to rely on the professionalism of the obstetrics teams. At the same time, the women had not been empowered and, although the sense of self-efficacy rose, it did not rise significantly.

Romano and Lothean ${ }^{[27]}$ suggested that the contents transmitted in the preparation courses reinforce the belief that medical technology and intervention ensure a safe and orderly birth, but do not promote the women's self-confidence or their ability and function in the childbirth process. The current study results point to a positive and significant effect of the childbirth preparation courses on reducing the level of anxiety of the nulliparous parturient who participated in the childbirth preparation course. Nevertheless, there were no differences between the anxiety level of women who attended the childbirth preparation course, and those who did not. One possible explanation of these results could be found in the fact that women participating in childbirth preparation courses have a stronger tendency toward anxiety than those who did not attend the course. Another explanation may be related to educational differences between the groups. The control group (no course) had a lower educational level than the participants in the childbirth preparation courses 
(60\% with of the controls had an academic education compared with $80 \%$ of the participants). It is also possible that viewing information and knowledge on the part of women holding academic degrees who have greater access to current information on health in general, and pregnancy and birth in particular, lead to higher levels of anxiety. Pregnancy and childbirth among those women are considered a medical event, and they regard it as an illness or an unhealthy state with a high degree of risks and complications. Acquiring a large amount of medical information and knowledge without the ability to professionally and critically reading that information increases anxiety, although it was reduced in the course of training provided by the midwife in the childbirth preparation course. From this we may deduce that the childbirth preparation courses offer substantial added value, which may stem from the group process activated during the courses. It could also be that the group process creates a support framework which reduces anxiety, and thus increases the sense of self-efficacy.

This study has several limitations. Firstly, the convenience sample strategy used in this study to collect data limits the ability to generalize findings. Secondly, the number of participants in each group was small. Had the number of participants in each group been greater, it is possible that a significant effect on the sense of self-efficacy would have been observed. Thirdly, self-efficacy is a multidimensional dynamic concept that undergoes change during pregnancy. Further research is needed to investigate levels of self-efficacy not only before and after childbirth preparation classes, but also close to labor and delivery. Additionally, in this study, only the state of anxiety during pregnancy was investigated. It would be worthwhile to examine whether any relationship exists between State-Trait anxiety of pregnant women who participate in childbirth preparation classes with State-Trait anxiety of those who do not.

\section{Conclusions}

Pregnancy and birth is a natural stage in a woman's life, and preparation for childbirth helps make it a positive experience. In general, the findings of the current study validate the importance of childbirth preparation courses. At the same time, based on the results of other studies and on those of the current study in particular, recommendations should be made regarding the focus of the contents in childbirth preparation courses, primarily on empowering women to cope with the natural childbirth process, rather than providing medical information and knowledge.

It is strongly recommended that nurses and midwives be trained to direct patients in general, and pregnant mothers in particular, toward intelligent consumership based on critical analysis of scientifically based medical and health information. The current study findings pose a challenge to the community of nurses and midwives to re-evaluate the effectiveness of the childbirth preparation courses after delivery as well. Such additional studies will significantly contribute to women's perception of the importance of attending childbirth preparation courses, empower the women, and assist them in coping with the childbirth process.

\section{CONFlicts OF InTEREST Disclosure}

The authors declare they have no conflict of interest.

\section{REFERENCES}

[1] Fleming G, Mckenna M, Murchison V, et al. Using self-efficacy as a client-centred outcome measure. Nursing Standard. 2003Jul; 17(34): 33-6. http://dx.doi.org/10.7748/ns2003.05.17.34 .33. 3386

[2] Toohill J, Fenwick J, Gamble J, et al. A Randomized Controlled Trial of a Psycho-Education Intervention by Midwives in Reducing Childbirth Fear in Pregnant Women. Birth. 2014 Sep; 41(4): 384-94. PMid: 25303111. http://dx.doi.org/10.1111/birt.12136

[3] Salomonsson B, Gullberg MT, Alehagen S, et al. Self-efficacy beliefs and fear of childbirth in nulliparous women. Journal of Psychosomatic Obstetrics \& Gynecology. 2013; 34(3): 116-21. PMid: 23952169. http://dx.doi.org/10.3109/0167482X.20 13.824418

[4] Soet JE, Brack GA, Diiorio C. Prevalence and Predictors of Women's Experience of Psychological Trauma During Childbirth. Birth. 2003; 30(1): 36-46. PMid: 12581038. http://data.worldbank.org/i ndicator/SH.XPD.PCAP

[5] Federal Ministry of Health Revised National Health Policy. Federal Ministry of Health (FMOH), Abuja, Nigeria. 2004. http:

\section{//dx.doi.org/10.1002/nur.4770160209}

[6] Reck C, Zimmer K, Dubber S, et al. The influence of general anxiety and childbirth-specific anxiety on birth outcome. Archives of Women's Mental Health Arch Womens Ment Health. 2013 May; 16(5): 363-9. PMid: 23558948. http://dx.doi.org/10.1007/s 00737-013-0344-0

[7] Beebe KR, Lee KA, Carrieri-Kohlman V, et al. The Effects of Childbirth Self-Efficacy and Anxiety During Pregnancy on Prehospitalization Labor. Journal of Obstetric, Gynecologic \& Neonatal Nursing. 2007; 36(5): 410-8. PMid: 17880311. http://dx.doi.org/10. $1111 / j .1552-6909.2007 .00170 \cdot x$

[8] Schwartz L, Toohill J, Creedy DK, et al. Factors associated with childbirth self-efficacy in Australian childbearing women. BMC Pregnancy Childbirth BMC Pregnancy and Childbirth. 2015; 15(1): 29. PMid: 25879780. http://dx.doi.org/10.1186/s12884-015 $-0465-8$

[9] Dilks FM, Beal JA. Role of Self-Efficacy in Birth Choice. The Journal of Perinatal \& Neonatal Nursing. 1997; 11(1): 1-9. http: //dx.doi.org/10.1097/00005237-199706000-00003 
[10] Heinze SD, Sleigh MJ. Epidural or no epidural anaesthesia: Relationships between beliefs about childbirth and pain control choices. CJRI J of Reproductive \& Infant Psych Journal of Reproductive and Infant Psychology. 2003; 21(4):323-33. http://dx . doi .org/10. 1080/02646830310001622132

[11] Christiaens W, Bracke P. Assessment of social psychological determinants of satisfaction with childbirth in a cross-national perspective. BMC Pregnancy Childbirth BMC Pregnancy and Childbirth. 2007; 7(1): 26. PMid: 17963491. http://dx.doi.org/10.1186/147 1-2393-7-26

[12] Berentson-Shaw J, Scott KM, Jose PE. Do self-efficacy beliefs predict the primiparous labour and birth experience? A longitudinal study. Journal of Reproductive and Infant Psychology. 2009; 27(4): 357-73. http://dx.doi.org/10.1080/02646830903190888

[13] Spinelli A, Baglio G, Donati S, et al. Do antenatal classes benefit the mother and her baby? The Journal of Maternal-Fetal \& Neonatal Medicine. 2003; 13(2): 94-101. PMid: 12735409. http://dx.doi.org/10.1080/jmf.13.2.94.101

[14] Byrne J, Hauck Y, Fisher C, et al. Effectiveness of a MindfulnessBased Childbirth Education Pilot Study on Maternal Self-Efficacy and Fear of Childbirth. Journal of Midwifery \& Women's Health. 2013 Oct; 59(2): 192-7. PMid: 24325752. http://dx.doi.org/1 $0.1111 /$ jmwh. 12075

[15] Bergström M, Kieler H, Waldenström U. Effects of natural childbirth preparation versus standard antenatal education on epidural rates, experience of childbirth and parental stress in mothers and fathers: a randomised controlled multicentre trial. BJOG: An International Journal of Obstetrics \& Gynaecology. 2009; 116(9): 1167-76. PMid: 19538406. http://dx.doi.org/10.1111/j.1471-0528. 2009.02144.x

[16] Escott D, Slade P, Spiby H, et al. Preliminary evaluation of a coping strategy enhancement method of preparation for labour. Midwifery. 2005; 21(3): 278-91. PMid: 15967550. http://dx.doi.org/10. 1016/j.midw. 2004.12.009
[17] Fabian HM, Radestad IJ, Waldenstrom U. Childbirth and parenthood education classes in Sweden. Women's opinion and possible outcomes. Acta Obstet Gynecol Scand. 2005; 84(5): 436-43. PMid: 15842207. http://dx.doi.org/10.1111/j.0001-6349. 2005.00732.x

[18] Spiby H, Slade P, Escott D, et al. Selected Coping Strategies in Labor: An Investigation of Women's Experiences. Birth. 2003; 30(3): 189-94. PMid: 12911802. http://dx.doi.org/10.1046/j.152 3-536X. 2003.00244.x

[19] Gagnon AJ, Sandall J. Individual or group antenatal education for childbirth or parenthood, or both. Cochrane Database of Systematic Reviews Reviews. 2007. http://dx.doi.org/10.1002/146 51858. cd002869.pub2

[20] Bandura A. Social learning theory. Englewood Cliffs, NJ: Prentice Hall; 1977.

[21] Bandura A. Social foundations of thought and action: a social cognitive theory. Englewood Cliffs, NJ: Prentice-Hall; 1986.

[22] Spielberger CD. State-trait anxiety inventory: a comprehensive bibliography. Palo Alto, CA: Consulting Psychologists Press; 1984.

[23] Etzion D, Tuval A, Berkenstein H. Correlation between psychological, physiological and behavioral indices under conditions of stress. Tel-Aviv: Tel-Aviv University. 2007.

[24] Lowe NK. Self-efficacy for labor and childbirth fears in nulliparous pregnant women. J Psychosom Obstet Gynecolol. 2000; 21(4): 21924. http://dx.doi.org/10.3109/01674820009085591

[25] Ip W-Y, Chan D, Chien W-T. Chinese Version of the Childbirth Self-Efficacy Inventory. PsycTESTS Dataset. 2015.

[26] Sinclair M, O’boyle C. The Childbirth Self-Efficacy Inventory: a replication study. J Adv Nurs Journal of Advanced Nursing. 1999; 30(6): 1416-23. PMid: 10583653. http://dx.doi.org/10.1046 /j.1365-2648.1999.01230.x

[27] Romano AM, Lothian JA. Promoting, Protecting, and Supporting Normal Birth: A Look at the Evidence. Journal of Obstetric, Gynecologic \& Neonatal Nursing. 2008; 37(1): 94-105. 